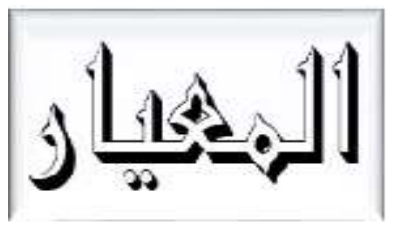

Al Mi'yar

Vol. 3, No. 1, April 2020

P-ISSN: 2620-6749, E-ISSN: 2620-6536

DOI: $10.35931 / a m . v 3 i 1.201$

\title{
REFLEKSI DAURAH TADRIBIYAH DI UNIVERSITAS UMM AL QURA MEKKAH SAUDI ARABIA
}

\author{
Farid Permana \\ STIQ Amuntai Kalimantan Selatan Indonesia \\ Email: Faried88@gmail.com
}

\begin{abstract}
Almost of all universities in Saudi Arabia have Arabic learning program for non Arab student, one of them is Arabic language institute for non Arabic speakers at Umm Alqura university in Mecca. As a holders responsibility for developing and expanding the Arabic language, this Institute in collaboration with the kingdom of Saudi Arabia has implemented a training program to strengthen Arabic learning for Islamic boarding school teachers, teachers and Arabic lecturers from Indonesia and Senegal.on 13 Shawwal - 20 Dzulqaidah 1439 coincides with June 28 - August 4, 2018. The various learning activities in this program include Arabic language, Islam and cultural insights that designed professionally. Based on the author's observations during became a participant in this program 2018. It's can be a very good reflection for developing Arabic learning programs in Indonesia, especially from attitude aspects, and teaching management. The author also recommends Arabic educators in Indonesia to take part in the Daurah to enrich Arabic learning techniques.
\end{abstract}

Keywords: Shortcourse, Arabic Learning, Umm Al Qura

\section{PENDAHULUAN}

Sebagai bahasa yang mendunia, bahasa Arab memainkan peranan penting bagi jutaan umat di seluruh dunia. Di samping untuk memahami teksteks kitab suci Alquran dan hadis sebagai dua sumber utama Islam, bahasa Arab juga dipelajari, diteliti dan dikembangkan sebagai alat untuk berkomunikasi baik secara lisan maupun tulisan. Hal tersebut tidaklah dapat dipungkiri bahwa dengan muncul dan menjamurnya sekolah-sekolah, pondokpondok pesantren dan pendidikan tinggi yang mempelajari bahasa Arab di 
Farid Permana: Refleksi Daurah Tadribiyah Di Universitas Umm Al Qura Mekkah Saudi Arabia

berbagai belahan dunia merupakan bukti berkembangnya pembelajaran bahasa Arab hingga akhir abad ini.

Salah satu di antara sekian banyak lembaga pendidikan tinggi yang konsen dan serius memerhatikan perkembangan pembelajaran bahasa Arab bagi penutur non Arab adalah Ma'had al-Lugah al-Arabiyah Ligairi alNathiqina Biha di Universitas Umm al-Qura Mekkah Saudi Arabia. Ma'had ini melaksanakan program pembelajaran bahasa Arab untuk mahasiswa non Arab, pendidikan guru bahasa Arab untuk non Arab dan program pelatihan pemantapan pengajar bahasa Arab untuk non Arab.

Program-program Ma'had di atas dimaksudkan untuk memberikan kesempatan bagi mahasiswa maupun pengajar non Arab untuk belajar dan menguasai bahasa Arab dan budayanya secara langsung melalui lingkungan aslinya. Mahasiswa asing yang ingin belajar pada berbagai jurusan di Universitas Umm al-Qura diharuskan untuk mengikuti program yang ada di Ma'had dalam jangka waktu tertentu, hal ini bertujuan untuk membekali pengetahuan bahasa Arab agar mudah memahami materi yang disampaikan ketika masuk kuliah.

Ma'had ini memiliki tanggung jawab dan kepedulian terhadap penyebaran dan perluasan pendidikan bahasa Arab, di samping itu pula Ma'had ini juga memiliki kepedulian untuk ikut serta dalam meningkatkan sumber daya manusianya yaitu pengajar bahasa Arab non Arab seperti guru, ustadz pesantren dan dosen.

Terkait pentingnya lembaga pendidikan memiliki kepedulian terhadap pengajar bahasa Arab, A. Suriansyah menyebutkan bahwa peningkatan kualitas komponen pendidikan yang paling berpengaruh terhadap peningkatan mutu pendidikan (bahasa Arab) adalah komponen sumber daya manusia atau human recources yaitu guru dan tenaga kependidikan lainnya karena komponen ini yang secara langsung maupun tidak langsung mempengaruhi kegiatan belajar mengajar di sekolah. Sebab komponen material seperti alat pembelajaran, alat peraga, laboratorium, dan sebagainya tidak akan bermanfaat tanpa adanya manusia yang mampu menggunakannya secara tepat dalam proses belajar mengajar. ${ }^{1}$

${ }^{1}$ A. Suriansyah, Aslamiyah Ahmad dan Sulistiyana. Profesi Kependidikan: Perspektif Guru Profesional. (Jakarta: Rajawali Pers. 2015). h, 145 
Farid Permana: Refleksi Daurah Tadribiyah Di Universitas Umm Al Qura Mekkah Saudi Arabia

Sementara itu Moekijat menjelaskan bahwa pengembangan sumber daya manusia bertujuan untuk mengembangkan keahlian atau keterampilan, pengetahuan dan sikap sehingga pekerjaan dapat diselesaikan lebih cepat, lebih efektif dan rasional serta menimblkan kerja sama dengan teman seprofesi dan pimpinan. ${ }^{2}$

Hal di atas diperkuat dengan hasil temuan Yasin tentang pengembangan pedagogik sumber daya manusia yaitu, telah terjadi perbaikan proses pembelajaran sesuai dengan tuntutan dunia pembelajaran modern dan telah terjadi perbaikan kinerja guru dalam pembelajaran sehingga berimplikasi pada mutu/prestasi hasil belajar peserta didik, baik akademik maupun non-akademik. ${ }^{3}$

Melihat kepada hasil temuan Syuhendri saat pelatihan singkat di New Zealand terkait pengembangan sumber daya seutuhnya dia mengungkapkan bahwa pengembangan sumberdaya manusia di New Zealand memiliki tiga pilar penunjang visi pendidikan yaitu value, key competencies dan learning area. $^{4}$

Pendapat di atas adalah sebuah isyarat bahwa program pembinaan terhadap para pengajar bahasa Arab sudah semestinya diadakan dan dikembangkan secara terus-menerus agar dapat melakukan fungsinya secara profesional.

Sehubungan dengan itu, Ma'had al-Lugah al-Arabiyah Ligairi alNathiqina Biha di Universitas Umm al-Qura bekerja sama dengan kerajaan Saudi Arabia dan Republik Indonesia melaksanakan sebuah program pelatihan pemantapan kualitas pengajaran bahasa Arab bagi pengajar bahasa Arab non Arab. Pelatihan ini dilatar belakangi oleh adanya rasa kepedulian yang tinggi ketiga pihak ini terhadap perkembangan pembelajaran bahasa Arab yang ada di Indonesia. Pelatihan ini diberi nama al-Daurah al-Tadribiyah

2 Moekijat. Pengembangan dan Motivasi (Bandung: Pionir Jaya. 1990) h. 17

${ }^{3}$ Ahmad Fatah Yasin, Pengembangan Kompetensi Pedagogik Guru Pendidikan Agama Islam di Madrasah (Studi Kasus di MIN Malang I), "Jurnal eL-Qudwah Vol.1Nomor 5 edisi April 2011: h. 178.

${ }^{4}$ Syuhendri, Pengelolaan Sekolah Untuk Mengembangkan Sumber Daya Manusia dan Implementasinya Pada Pembelaiaran IPA SD: Suatu Refleksi Hasil Short Course di New Zealand. 2012.

https://scholar.google.co.id/citations?user=2obM3zUAAAAJ\&hl=id\&oi=sra\#d=gs md cita$\mathrm{d} \& \mathrm{u}=\% 2 \mathrm{Fcitations} \% 3$ Fview op $\% 3$ Dview citation $\% 26 \mathrm{hl} \% 3 \mathrm{Did} \% 26 \mathrm{user} \% 3 \mathrm{D} 2 \mathrm{obM} 3 \mathrm{zUAAAAI}$ \%26cstart $\% 3 \mathrm{D} 20 \% 26$ pagesize $\% 3 \mathrm{D} 80 \%$ 26citation for view $\% 3 \mathrm{D} 2$ obM3zUAAAAJ\%3Ar0Bpnt ZqJG4C\%26tzom\%3D-480 
Farid Permana: Refleksi Daurah Tadribiyah Di Universitas Umm Al Qura Mekkah Saudi Arabia

al-Shaifiyyah Limu'allimi al-Lugah al-Arabiyah Lighairi al-Natiqina Biha Bi Jami'ah Umm al-Qura Mekkah 'Am 2018 M/1439H (Selanjutnya dibaca DTS 2018).

Penulis berkesempatan menjadi peserta daurah dan mengikuti kegiatan hingga tuntas. Maka dari itu tulisan ini mencoba merefleksikan kegiatan di atas sebagai bahan perbandingan dengan pengembangan pembelajaran bahasa Arab yang ada di Indonesia. Bagaimana persiapan dan rencana kegiatan, seleksi peserta, isi kegiatan DTS 2018 dan hasilnya serta refleksinya terhadap perkembangan pendidikan bahasa Arab di Indonesia. Semua ini menjadi pertanyaan menarik untuk dicari jawabannya.

Refleksi serupa tentang kurikulum pendidikan bahasa Arab di Universitas Malik Su'ud Riyadh telah dipaparkan oleh Hamid, menurutnya kurikulum di sana merupakan sebuah program yang dikhususkan untuk mempersiapkan tenaga pendidik bahasa Arab professional yang dapat dijadikan model dan bahan perbandingan dengan pembelajaran bahaa Arab di Indonesia. ${ }^{5} \mathrm{Hal}$ ini berarti program untuk pengadaan tenaga pendidik bahasa Arab profesioanal memang sudah menjadi program unggulan beberapa perguruan tinggi di Timur Tengah termasuk Universitas Umm Al Qura Mekkah.

\section{METODE PENELITIAN}

Dalam kajian ini penulis menggunakan metode deskriptif analitatif melalui data yang diperoleh dengan teknik observasi partisipan, wawancara dan dokumentasi. Kemudian data dianalisis dan ditafsirkan sesuai dengan realita dan konteks yang ada.

Penelitian ini berusaha mencari deskripsi, analisis sebuah kegiatan dan mengamati peristiwa yang terjadi dalam peroses berlangsungnya kegiatan DTS di Universitas Umm al Qura Mekkah Tahun 2018. Maka penelitian ini Menurut Bogdan dan Taylor sebagaimana dikutip Moleong dapat dikatakan berpendekatan kualitatif yaitu prosedur penelitian yang menghasilkan data

${ }^{5}$ Muhammad Abdul Hamid, Dirasah 'An Manhaj Ta'lim al-Lugah Al-Arabiyah Ligairi AlNathiqina Biha Bijami'ah Al-Malik Sa'ud Fi Al Riyadh , Jurnal Al Jadid, Vol. 8 Nomor 1, 2008: h. 142 
Farid Permana: Refleksi Daurah Tadribiyah Di Universitas Umm Al Qura Mekkah Saudi Arabia

deskriptif berupa kata-kata tertulis atau lisan dari orang-orang dan perilaku yang dapat diamati dan diarahkan pada latar dan individu secara utuh. ${ }^{6}$

Penelitian ini berjenis studi kasus (case studies) yaitu penelitian tentang suatu kesatuan sistem yang berupa program, kegiatan, peristiwa atau sekolompok individu yang terkait oleh tempat, waktu dan ikatatan yanag telah ditentukan. Studi kasus bertujuan untuk menghimpun data, mengambil makna, dan memperoleh pemahaman dari kasus tersebut. ${ }^{7}$

Penelitian ini bertempat di Universitas Umm Al Qura Mekkah Saudi Arabia dengan rentang waktu dari tanggal 28 Juni hingga 04 Agustus 2018 atau sekitar 5 pekan/ 37 hari.

\section{HASIL DAN PEMBAHASAN}

\section{Program Daurah Rencana dan Persiapannya}

Seperti yang telah disampaikan di atas, berdasarkan hasil wawancara dengan pihak panitia bahwa kegiatan DTS ini diadakan oleh Universitas Umm al-Qura Makkah atas persetujuan kerajaan Saudi. Sebagai penghubung antara Indonesia dengan Saudi Arabia, pihak Umm al-Qura telah menentukan tim di Indonesia berkaitan dengan pelaksanaan DTS ini, yaitu Pondok Pesantren Darunnajah Ulujami Jakarta.

Lembaga ini telah menjalin kerjasama dengan Umm al-Qura sejak kurang lebih 10 tahun silam. Koordinator utama di Indonesia untuk kegiatan DTS ini adalah Ust. Dr. KH. Sofwan Manaf, M.A (Kepala Pondok), Ust. Dr. Faisal Hendra, M.Ed (Dekan UAI Jakarta), dan Ust. Nur Hizbullah, S.Ag.,M.Hum (Ketua Jurusan Sastra Arab UAI Jakarta).

Kegiatan ini diberi nama al-Daurah al-Tadribiyah al-Shaifiyyah Limu'allimi al-Lugah al-Arabiyah Lighairi al-Natiqina Biha Bi Jami'ah Umm alQura Mekkah 'Am 2018 M/1439H atau Kursus Pelatihan Pengajar Bahasa Arab untuk Penutur Non Arab di Universitas Umm al-Qura Mekkah Musim Panas Tahun 2018 Masehi/1439 Hijriah. Bertempat di Universitas Umm al-Qura

h. 4

${ }^{6}$ Moloeng, Lexy J. 2011 Metodologi Penelitian Kualitatif (Bandung: Rosdakarya. 2011).

7 Ghony Djunaidi \& Almanshur Fauzan, Metodologi Penelitian kualitatif, (JogJakarta: Ar-Ruzz Media.2012). h. 62. 
Farid Permana: Refleksi Daurah Tadribiyah Di Universitas Umm Al Qura Mekkah Saudi Arabia

Mekkah dan dilaksanakan mulai dari tanggal 28 Juni hingga 04 Agustus 2018 bertepatan dengan 13 Syawal hingga 20 Dzulqaidah $1439 \mathrm{H}$.

Tujuan utama dari kegiatan ini adalah untuk memantapkan kompetensi pedagogik pengajar bahasa Arab dalam merencanakan, melaksanakan dan mengevaluasi pembelajaran bahasa Arab. Di samping itu pula kegiatan DTS ini dimaksudkan untuk pematangan teori pembelajaran bahasa Arab, wawasan keislaman dan kebudayaan Arab.

Tujuan lain dari kegiatan ini sebagaimana yang dipaparkan oleh Syeikh Dr. Hasan Bukhari Dekan Fakultas Bahasa Arab untuk non Arab yang sekaligus Imam Masjid al-Haram yaitu 1) meningkatkan keimanan dan ketakwaan kepada Allah SWT, 2) meningkatkan kompetensi pengajar bahasa Arab dalam bidang keislaman, 3) meningkatkan kompetensi pembelajaran bahasa Arab bagi pengajar bahasa Arab baik tingkat madrasah, pondok pesantren maupun perguruan tinggi, 4) memberi wawasan yang luas kepada pengajar bahasa Arab tentang budaya Arab, 5) mengenalkan tempat-tempat bersejarah dan tempat yang berkontribusi dalam perkembangan dakwah Islam dan Pembelajaran bahasa Arab.

Rencana dan persiapan DTS dapat dikatakan telah memiliki mekanisme yang baik karena melibatkan banyak pihak dan didukung oleh fasilitas yang dimanfaatkan secara optimal.

\section{Proses Perekrutan Peserta DTS Umm Al Qura Mekkah 2018}

Sebelum melaksanakan kegiatan ini pihak Umm al-Qura sudah berkoordinasi dengan pihak dari pondok pesantren Darunnajah Jakarta untuk melaksanakan perekrutan peserta di Indonesia. Kegiatan ini sudah berlangsung kurang lebih sepuluh tahun dan setiap tahunnya menghasilkan 20 orang peserta DTS yang dipilih melalui tahap seleksi.

Berkaitan dangan tahap seleksi, pertama-tama Ponpes. Darunnajah menginformasikan kepada khalayak umum Indonesia terkait kegiatan DTS yang akan dilaksanakan meliputi informasi deskripsi DTS, waktu dan tata cara seleksi, persyaratan peserta, tahapan calon peserta, dan hal-hal yang penting lainnya yang ditulis dalam sebuah web.

Peserta DTS ini dibatasi hanya 20 orang se-Indonesia. Pengumuman dilakukan melalui website resmi www.darunnajah.com, via SMS dan WhatsApp (WA). Calon peserta mendaftarkan diri kepada PP. Darunnajah 
Farid Permana: Refleksi Daurah Tadribiyah Di Universitas Umm Al Qura Mekkah Saudi Arabia

dengan mengirimkan berkas yang sudah ditentukan, kemudian mengikuti wawancara via telepon.

Setiap pendaftar yang lulus berkas persyaratan DTS akan dihubungi via telepon oleh pihak panitia seleksi. Materi wawancara meliputi identitas diri, latar belakang pendidikan, tempat mengajar dan beberapa pertanyaan terkait dengan minat, tujuan dan kompetensi penguasaan bahasa Arab calon peserta. Jika calon peserta dinyatakan lulus seleksi berkas dan wawancara, maka tahap berikutnya adalah panitia seleksi memastikan kembali kesiapan calon peserta untuk ikut DTS dan kemudian dilaporkan hasilnya kepada pihak Ummul Qura Mekkah dan kemudian dibuatkan ifadah dan visa dari Kementerian luar Negeri dan Kementerian Pendidikan Tinggi Saudi Arabia.

DTS ini sudah terlaksana sebanyak sembilan angkatan. Untuk tahun 2018 adalah angkatan yang ke sepuluh. Tahap seleksi dan pengumuman angkatan ke sepuluh ini sekitar bulan Desember 2015 dan akan diberangkatkan pada Syawal $1436 \mathrm{H}$ atau bertepatan pada bulan Juli 2016 Masehi. Namun demikian, keberangkatan ditunda hingga kurang lebih tiga tahun karena faktor internal negara Kerajaan Saudi Arabia yang mengalami problema. Angkatan ke sepuluh ini baru akhirnya diberangkatkan pada 13 Syawal 1439 H. Atau bertepatan pada tanggal 28 Juni 2018.

\section{Proses Koordinasi Pra Keberangkatan}

Pasca perekrutan melalui seleksi berkas dan tes. Panitia DTS dianjurkan untuk mengaktifkan akun whatsapp yang digunakan untuk koordinasi dan penyebaran informasi terkait kesiapan dan persiapan DTS. Panitia DTS bertanggung jawab memastikan kesiapan peserta DTS melalui grup WA yang dibikin oleh panitia. Informasi utama di dalam grup WA tersebut meliputi kepastian keberangkatan, kesiapan peserta, perlengkapan, oleh-oleh untuk syiekh di Ummul Qura Mekkah, pakaian wajib peserta dan lain -lain.

Untuk memantapkan rencana dan persiapan peserta, maka panitia melalui grup WA memberikan informasi untuk berangkat dari daerah masingmasing menuju Pondok pesantren Darunnajah Ulujami Jakarta dua hari sebelum keberangkatan ke Mekkah. Hal ini dilakukan agar masing-masing peserta dapat berkenalan antar peserta dan panitia DTS. 
Farid Permana: Refleksi Daurah Tadribiyah Di Universitas Umm Al Qura Mekkah Saudi Arabia

Kegiatan pra keberangkatan meliputi perkenalan, pengarahanpengarahan berupa sharing pengalaman, hal teknis ketika di Mekkah, persiapan dan pelengkapan barang bawaan, manasik haji dan Umrah. Panitia menyampaikan beberapa hal terkait kegiatan dan sikap peserta DTS terhadap pelaksanaan kegiatan DTS ketika di Mekkah. Selain itu, panitia juga menyampaikan hal terkait ma ba'da daurah atau apa yang dilakukan pasca daurah. Peserta DTS diharapkan menjadi penggerak kegiatan kebahasa Araban di Indonesia.

Kegiatan lain pra keberangkatan DTS adalah penunjukan ketua rombongan, dan struktur komponen lainnya seperti sekretaris, bendahara, seksi acara, seksi ibadah, seksi perlengkapan dan dokumentasi. Kegiatan koordinasi dan persiapan pra keberangkatan DTS menjadi hal penting atau modal dasar untuk mengikuti DTS dengan baik.

Setiba hari keberangkatan, rombongan DTS berjumlah 19 orang berpoto bersama di halaman pondok pesanteren Darunnajah Jakarta kemudian berpamitan dengan panitia DTS sebelum akhirnya diberangkatkan ke bandara internasional menggunakan bis pondok. Koordinasi masih dilakukan hingga kegiatan chek in berlangsung dan terakhir, rombongan DTS di lepas untuk diberangkatkan pukul 10.40 WIB menggunakan Pesawat Saudia rute Jakarta-Jeddah.

\section{Kegiatan DTS Umm Al Qura Mekkah 2018}

Kedatangan rombongan DTS di bandara King Abdul Aziz Jeddah disambut baik oleh dua orang perwakilan kampus Umm al Qura Mekkah. Rombongan sepakat untuk berniat ihram dan memakai kain ihram di bandara serta melaksanakan ibadah umrah setiba di Mekkah. Dibutuhkan waktu sekitar 2 jam menuju Mekkah dari bandara Jeddah.

Setibanya di Mekkah, rombongan DTS ditempatkan di apartemen al wifadah al roqiah sekitaran daerah bernama Batha Quraisy. Apartemen tersebut letaknya relatif jauh dengan kampus Umm al Qura yaitu sekitar 7 kilometer. Adapun menuju mesjid al haram kurang lebih sekitar 5 kilometer. Setelah meletakkan barang di kamar masing-masing dan makan malam, rombongan diinstruksikan untuk istirahat dan melaksanakan umrah pada pagi hari pukul 05.00 pagi. 
Farid Permana: Refleksi Daurah Tadribiyah Di Universitas Umm Al Qura Mekkah Saudi Arabia

Pada Jumat 29 Juni 2018, Syeikh Hasan Bukhari selaku pimpinan penyelenggara DTS datang dan mengucapkan selamat datang kepada rombongon kemudian melaksanakan temu formal di ruang pertemuan apartemen. Banyak arahan yang disampaikan terkait dengan informasi kegiatan DTS yang akan dilaksanakan.

\section{Kegiatan di dalam kelas}

Kegiatan DTS ini dilaksanakan selama lima minggu, sehingga kegiatan tatap muka di dalam kelas ada lima kali dalam seminggu. Pelaksanaan perkuliahan dimulai pada hari Ahad hingga Kamis dari jam 08.00 hingga 13.00. khusus untuk hari Ahad dan Senin, tatap muka berlanjut mulai pukul 16.20 hingga 22.00 malam hari.

Materi yang diperoleh oleh peserta DTS meliputi materi kebahasa Araban, keIslaman dan Pendidikan praktis terkait kompetensi pedagogik dan sikap. Di antara materi yang diajarkan adalah: 1) tadris anasir al lugah wa mufrodatiha, (2) Tadris al Nahwi lighairi al arab, (3) tadris maharah al Muhadasah wa al Istima', (4) qadhaya fiqhiyah muashirah, (5) tadris maharah al qira'ah wa al kitabah, (6) al ikhtibarat wa al taqwim, (7) madzahib fikriyah mua shiroh, (8) al tafsir wa ulum al Qur"an, (9) bina ì wa tadwir al manhaj, (10) al hadist wa ulumuhu.

Materi-materi di atas diajarkan dengan menggunakan pendekatan demokratis dan metode yang beragam meliputi metode ceramah, tanya jawab, grup diskusi dan praktek.

Sumber belajar diambil dari tulisan para syaikh dan beberapa dari internet. Materi sudah dipersiapkan lebih dahulu dan disusun ke dalam sebuah tulisan berbentuk diktat yang dibagikan ke semua peserta DTS.

Penyampaian materi di atas diampu oleh delapan dosen bergelar doktor yang ahli dalam bidangnya. Dengan memanfaatkan dukungan fasilitas yang lengkap, para dosen sangat leluasa dalam mengajar selama dua kali 60 menit. Medianya meliputi komputer, proyektor dan papan tulis responsif.

Berikut ini adalah aktifitas di dalam kelas harian yang harus diikuti peserta DTS di Universitas Umm al Qura Mekkah Tahun 2018.

Tabel 1. Jadwal Kelas Pagi Program Daurah 2018

\begin{tabular}{|l|l|l|l|}
\hline No & Jam & Mata Kuliah & Dosen \\
\hline
\end{tabular}


Farid Permana: Refleksi Daurah Tadribiyah Di Universitas Umm Al Qura Mekkah Saudi Arabia

\begin{tabular}{|c|c|c|c|}
\hline \multicolumn{4}{|c|}{ Hari Ahad } \\
\hline 1 & $08.00-11.00$ & $\begin{array}{l}\text { tadris anasir al lugah wa } \\
\text { mufrodatiha }\end{array}$ & Dr. Maimun \\
\hline 2 & $11.00-13.00$ & $\begin{array}{l}\text { Tadris al Nahwi lighairi al } \\
\text { arab }\end{array}$ & Dr. Abdul Aziz Thalhi \\
\hline \multicolumn{4}{|c|}{ Hari Senin } \\
\hline 1 & $08.00-11.00$ & $\begin{array}{l}\text { tadris maharah al Muhadasah } \\
\text { wa al Istima' }\end{array}$ & Dr. Arif Al Ushaimi \\
\hline 2 & $11.00-13.00$ & qadhaya fiqhiyah muashirah & Dr. Sholeh Al Mab'us \\
\hline \multicolumn{4}{|c|}{ Hari Selasa } \\
\hline 1 & $08.00-11.00$ & $\begin{array}{l}\text { tadris maharah al qira'ah wa } \\
\text { al kitabah }\end{array}$ & Dr. Al Haritsi \\
\hline 2 & $11.00-13.00$ & al ikhtibarat wa al taqwim, & Dr. Juaidi \\
\hline \multicolumn{4}{|c|}{ Hari Rabu } \\
\hline 1 & $08.00-10.00$ & madzahib fikriyah mua shiroh & Dr. Qoshir \\
\hline 2 & $10.00-12.00$ & al tafsir wa ulum al Qur"an, & Dr. Misy'al al Ghomidi \\
\hline \multicolumn{4}{|c|}{ Hari Kamis } \\
\hline 1 & $08.00-10.00$ & bina i wa tadwir al manhaj, & Dr. Juaidi \\
\hline 2 & $10.00-12.00$ & al hadist wa ulumuhu & Dr. Qoshir \\
\hline
\end{tabular}

Disamping materi-materi tersebut di atas ada materi tambahan yang dilaksanakan pada jam 16.30-22.00. kegitan tambahan ini juga dilaksnakan di dalam ruang kuliah dan diberi nama Nasyath Masa'i atau program Sore. Kegiatan ini khusus dilaksanakan pada hari Ahad dan Senin Sore meliputi praktek pembelajaran dan sedikit teori dan sharing antar peserta terkait dengan materi fann al khitabah, tathbiq maharah al kitabah wa al qira'ah. Tathbiq maharah al kalam wa al istima' dan lain-lain. Lebih jelasnya diterangkan pada tabel berikut ini.

Tabel 2. Jadwal Kelas Sore Program Daurah 2018

\begin{tabular}{|l|l|c|l|l|}
\hline No & Pekan/Tanggal & Hari/Jam & Mata Kuliah & \multicolumn{1}{|c|}{ Dosen } \\
\hline 1 & I/01 Juli 2018 & Ahad, & Fannu khitabah & Dr. Misy'al al \\
& & $16.30-$ & & Ghomidi \\
& & 21.00 & & \\
\hline 2 & I/02 Juli 2018 & Senin, & Fannu al khitabah wa & Prof. Dr. Sholeh \\
& & $16.30-$ & fann Idarah al & Mab`us \\
\hline
\end{tabular}


Farid Permana: Refleksi Daurah Tadribiyah Di Universitas Umm Al Qura Mekkah Saudi Arabia

\begin{tabular}{|c|c|c|c|c|}
\hline & & 21.00 & madrasah & \\
\hline 3 & II/08 Juli 2018 & $\begin{array}{l}\text { Ahad, } \\
16.30- \\
21.00\end{array}$ & $\begin{array}{l}\text { Maharah kalam wa } \\
\text { istima }\end{array}$ & Dr. Arif Suja`an \\
\hline 4 & II/09 Juli 2018 & $\begin{array}{l}\text { Senin, } \\
16.30- \\
21.00\end{array}$ & Maharah qiro`ah & $\begin{array}{l}\text { Dr. } \\
\text { Abdurrahman } \\
\text { Qosir }\end{array}$ \\
\hline 5 & III/15 Juli 2018 & $\begin{array}{l}\text { Ahad, } \\
16.30- \\
21.00\end{array}$ & Tadris anasirul lughah & Dr. Maimun \\
\hline 6 & III/15 Juli 2018 & $\begin{array}{l}\text { Senin, } \\
16.30- \\
21.00\end{array}$ & $\begin{array}{l}\text { Tadris maharah } \\
\text { qiroah wa kitabah }\end{array}$ & Dr. Ali al Harisi \\
\hline 7 & IV/22 Juli 2018 & $\begin{array}{l}\text { Ahad, } \\
16.30- \\
21.00\end{array}$ & $\begin{array}{l}\text { Bina al Manahij wa } \\
\text { tathwiruha }\end{array}$ & Dr. Juaidi \\
\hline 8 & IV/23 Juli 2018 & $\begin{array}{l}\text { Senin, } \\
16.30- \\
21.00\end{array}$ & $\begin{array}{l}\text { Ta'lim al Musaggar } \\
\text { limadah Nahwi lighairi } \\
\text { arab }\end{array}$ & $\begin{array}{l}\text { Dr. Abdul Aziz } \\
\text { at Talhi }\end{array}$ \\
\hline
\end{tabular}

\section{Kegiatan Ziarah Sosial Budaya Arab}

Ziarah budaya adalah kegiatan di luar kelas dalam bentuk kunjungankunjungan ke tempat-tempat bersejarah, ke rumah para syaikh, lembagalembaga pendidikan, badan wakaf dan instansi lainnya. Kegiatan ini bertujuan untuk mengenalkan peserta DTS dengan budaya Arab, tempat bersejarah, tokoh-tokoh penting di Mekkah, dan lembaga-lembaga penting lainnya. Kegiatan ziarah sosial budaya Arab ini mencakup tiga kota yaitu kota Mekkah, kota Thaif dan kota Madinah.

Adapun ziarah sosial budaya Arab pada program DTS tahun $2018 \mathrm{di}$ kota Mekkah dan kota Thaif berupa: a) Kunjungan ke Arafah, Mesjid Namirah dan Jabal Rahmah, Jabal Tsaur dan Jabal Nur goa Hira; b) kunjungan ke pasar 

Arabia

Ukaz di Thaif; ${ }^{8}$ c) Kunjungan ke kediaman Syekh Faisal al Ghazawi (imam Mesjid al Haram Mekkah); d) kunjungan ke bukit shafa di Thaif; ${ }^{9}$ e) Kunjungan ke Mesjid Jami dan lembaga sosial dan dakwah Al Rajhi; f) Kunjungan ke Hudaibiyah dan Museum Pembangunan Mesjid al Haram; g) halaqah Tahfizh Mesjid Asyur Bukhari Mekkah; h) Maktab Hadiah Haji dan Umrah; i) Kunjungan ke Muzdalifah, Mina dan Jabal Nur; j) kunjungan ke kediaman Muadzin Mesjid al Haram; k) kunjungan ke lembaga pengembangan bahasa Arab di Mekkah.

Ziarah sosial Budaya Arab selanjutnya adalah kunjungan budaya di kota Mandinah. Kegiatan ini berlangsung selama tiga hari yaitu berupa kunjungan a) Mesjid Nabawi; b) Raudhah dan makam Nabi Muhammad, SAW. c) makam sahabat Nabi di Baki'; d) kunjungan ke Uhud dan makam Syuhada Uhud; e) sholat di Mesjid Quba; f) mesjid Qiblatain dan mesjid Jumuah; g) kunjungan ke museum dakawah mesjid Nabawi; dan h) kunjungan ke pasar Kurma.

Semua kegiatan Ziarah Sosial Budaya diberangi dengan presentasi dari para doktor mengenai sejarah, program-program dan struktur organisasi yang ada pada tempat-tempat yang dikunjungi. Diharapkan dari pesan-pesan yang disampaikan langsung oleh para narasumber tersebut, peserta DTS bisa menghayati perjuangan dakwah Nabi dan memahami nilai-nilai budaya yang dimiliki oleh orang-orang Arab.

Menurut hasil wawancara dengan Dr. Misy'al Al Gomidy selaku pengampu program Ziarah Sosial Budaya bahwasanya kegiatan ziarah ini bagian dari peningkatan kompetensi pengajar bahasa Arab mengenai budaya asli orang Arab. Para pengajar tidak hanya menguasai bahasa Arab namun juga memahami nilai budaya yang dianut oleh orang Arab.

8 Pasar Ukaz adalah sebuah tempat di sekitaran distrik kota Thaif di mana di dalamnya terdapat pameran seni budaya Arab seperti pameran sejarah mushaf-mushaf Alquran, sejarah syi'ir Arab Jahiliy, Sejarah Khat al Araby, benda-benda sejarah, pementasan Seni budaya, humor dan lain-lain. Hasil kunjungan observasi pada tanggal 08 Juli 2018.

${ }_{9}$ Bukit Shafa adalah salah satu bukit sejuk tempat rekreasi orang Arab. Berjarak 150 KM dari kota Mekkah. Di dalamnya ada pemandangan indah, kemah dan bangunan yang didesain seperti zaman Arab jahiliyah dan zaman Nabi. Contohnya seperti kemah kaum Quraisy dan bangunan beratap pelapah-pelapah kurma. Hasil Observasi 
Farid Permana: Refleksi Daurah Tadribiyah Di Universitas Umm Al Qura Mekkah Saudi Arabia

\section{Faktor Pendukung kegiatan DTS Umm Al Qura Mekkah tahun 2018}

Berdasarkan pengamatan langsung terhadap berjalannya proses kegiatan DTS tahun 2018. Ada beberapa faktor pendukung yang dapat dipaparkan pada hasil kajian kali ini. Beberapa faktor ini memiliki kontribusi yang dominina terhadap kualitas berlangsungnya program ini.

Di antara faktor pendukung tersebut adalah adanya mekanisme menejemen yang baik terhadap pelaksanaan program DTS ini. Mulai dari mekanisme perekrutan peserta, transportasi, akomodasi dan manajemen di dalam dan di luar kel

ada aspek lain yang didapati tanpa ada perencanaan namun semuanya tetap bisa berlangsung.

Faktor pendukung lainnya berupa moda transportasi yang nyaman dan selalu siap untuk mengantarkan peserta DTS 2018 ke kampus, beribadah ke masjid al Haram dan beberapa tempat bersejarah lainnya. Supir orang Indonesia yang berasal dari Madura ditunjuk khusus oleh pihak Umm al Qura Mekkah agar memudahkan peserta dalam berkomunikasi dan berinteraksi langsung dengannya. Selama kegiatan DTS ini, perserta DTS telah menjalin hubungan emosional yang baik terhadap sopir dan saling memberikan keuntungan dalam bekerjasama.

Dari aspek akomodasi dan konsumsi peneliti melihat hal ini juga sebagai faktor pendukung terpenting bagi kesiapan fisik dan mental peserta DTS. Fasilitas penginapan sudah standar berupa apartemen yang dekat dengan mesjid dan memliki empat tingkat dilengkapi dengan fasilitas yang lengkap dan baik seperti AC kulkas, mesin cuci, televisi, Wifi dal lainnya. Dari segi konsumsi pihak Umm al Qura Mekkah menghidangkan makanan sebanyak tiga kali dalam sehari dengan menu di atas standar dengan menempatkan pegawai konsumsi yang siap melayani peserta DTS. Pada kesempatan lainnya seperti di dalam kelas dan kegiatan kunjungan, konsumsi juga disediakan secara lengkap. Peneliti melihat seakan-akan orang Arab memiliki budaya memuliakan tamu yang luar biasa tingginya. Sehingga para tamu tidak akan dibiarkan merasa lapar dan dahaga saat berkunjung ke rumahnya.

Faktor pendukung berikutnya adalah adanya perlakuan yang baik dari pihak Umm al Qura Mekkah terhadap peserta DTS. Berdasarkan pengamatan 
Farid Permana: Refleksi Daurah Tadribiyah Di Universitas Umm Al Qura Mekkah Saudi Arabia

peneliti, wajah-wajah ikhlash, cerah dan gembira dari para mutadarrib selalu terlihat. Hal inilah yang membuat para peserta tetap semangat mengikuti jalannya program DTS ini.

Berdasarkan hal di atas dapat disimpulkan bahwa kegiatan DTS menjadi sangat berarti apabila ada faktor-faktor lain yang mendukung pelaksanaannya. Seperti adanya menejemen yang baik, moda transportasi yang laik, akomodasi, konsumsi yang sesuai standar dan sikap baik yang ditunjukkan oleh orang-orang di lingkungan peserta.

\section{Kendala yang dihadapi Peserta DTS Umm Al Qura Mekkah Tahun 2018}

Sembilan belas peserta dari Indonesia pada program DTS Umm al Qura Mekkah tahun 2018 mempunyai kendala tersendiri dalam mengikuti program DTS 40 hari ini. Berdasarkan hasil pengamatan peneliti terhadap proses perjalanan program DTS ini ada kendala berupa miss komunikasi antara peserta DTS dengan pihak panitia sehingga terdapat beberapa agenda DTS yang tidak bisa dilaksanakan. Seperti kunjungan ketempat bersejarah yang batal dilaksanakan karena ketidak sepahaman dengan penetapan waktu keberangkatan. Terkadang ada beberapa program kunjungan yang dijadwalkan secara dadakan sehingga peserta DTS gelabakan dalam mempersiapkan diri untuk keberangkatan.

Berdasarkan hasil wawancara peneliti dengan beberapa peserta DTS, kendala yang paling mendasar yang dihadapi peserta adalah terlalu padatnya aktifitas harian yang harus dilalui, sehingga menimbulkan kelelahan fisik. Anwar salah seorang peserta mengatakan jadwal yang ditetapkan pihak panitia terlalu padat dan lama sehingga dirinya sering merasa lelah dan sedikit mengantuk ketika mengikuti pembelajaran di kelas. Berdasarkan hasil observasi peneliti ketika jam pelajaran berlangsung terdapat sebagian besar peserta yang mengantuk akibat kelelahan.

Terkait dengan kendala di atas peneliti mengamati waktu untuk istirahat sangatlah sedikit hanya sekitar 2 jam dalam seharian. Dari jam 08.00 hingga jam 10 malam. Hal ini berakibat lelah fisik dan otak karena harus menyerap pengetahuan dalam waktu yang berlangsung lama. Ditambah lagi dengan kegiatan kunjungan ziarah ke tempat bersejarah setiap hari kecuali hari Jum'at dan Sabtu. 
Farid Permana: Refleksi Daurah Tadribiyah Di Universitas Umm Al Qura Mekkah Saudi Arabia

Kendala berikutnya adalah adanya perbedaan adat dan kebiasaan dengan orang Arab dan peserta dari negara Senegal sehingga menyebabkan peserta dari Indonesia harus menyesuaikan diri. Berdasarkan pengamatan penulis, ada beberapa kali terjadi perselisihan antara peserta Indonesia dan Senegal atau Indonesia dan Arab karena adat kebiasaan yang berbeda. Misalnya kejadian tentang disiplin ketepatan waktu untuk berangkat ke kampus atau berangkat kunjungan. Adapula kejadian tentang waktu makan. Atau makanan yang kurang cocok dengan lidah peserta. Sering beberapa kali peserta mengeluhkan makanan yang disediakan itu-itu saja tanpa ada variasi atau ala Indonesia sehingga merasa bosan dan ingin mencari makanan khas nusantara.

\section{Refleksi DTS Umm al Qura Mekkah Tahun 2018 terhadap pendidikan bahasa Arab di Indonesia.}

Berdasarkan kajian yang dilakukan peneliti terhadap program DTS tadribiyah Umm al Qura Mekkah tahun 2018 ada beberapa refleksi yang bisa dipaparkan dalam rangka menilai dan mengamati apa yang telah terjadi selama kegiatan pelatihan atau kegiatan pembelajaran berlangsung.

Program DTS ini adalah program yang tidak biasa karena melibatkan dua negara dan banyak instansi pendidikan. Belum lagi materi yang disediakan semuanya tidaklah sedikit dan tidak bisa dianggap tanpa keseriusan. Hal ini harusnya bisa dimanfaatkan oleh banyak kalangan pemerhati pendidikan bahasa Arab di Indonesia. Karena dengan adanya program ini para pengajar dan pendidik bisa memahami budaya Arab dan meningkatkan kompetensi mengajar bahasa Arab mereka.

Peneliti mengamati akhir-akhir ini IMLA atau ikatan pengajar bahasa Arab di Indonesia telah mengimplementasikan program ini di berbagai wilayah di Indonesia. Hal ini dapat dikatakan bahwa sebagian pengajar bahasa Arab yang merupakan alumni DTS ini telah merespon positif terhadap kegiatan DTS Umm Al Qura Mekkah dalam rangka membumikan bahasa Arab di Indonesia.

Pada aspek pembelajaran bahasa Arab, kehadiran DTS ini menjadi wadah untuk sharing permasalahan dan mencari solusi bersama terkait dengan perkembangan pendidikan bahasa Arab. Bagian vital dari DTS ini adalah terdapat pada faktor penggerak seperti manajer yang merencanakan 
Farid Permana: Refleksi Daurah Tadribiyah Di Universitas Umm Al Qura Mekkah Saudi Arabia

dengan baik segala hal yang terkait dengan kelangsungan program DTS. Begitu pula dengan program-program pelatihan bahasa Arab di Indonesia. Aktor penggerak suatu program merupakan komponen terpenting dalam memajukan pendidikan bahasa Arab.

Para syaikh sekaligus pengajar melatihkan mata kuliah dengan hati yang ikhlas. Suasana keikhlasan ini dapat dirasakan oleh peserta DTS, terbukti dari cara mengajar mereka dengan wajah yang gembira, berbagi ilmu tanpa lelah, selalu memotivasi, berinteraksi dengan semua peserta dan saling berbagi pendapat. Hal ini pula lah yang harus dimiliki pengajar bahasa Arab di Indonesia. Datang tepat waktu dan menebar pesona muka senang dan ceria menjadi penyemangat belajar peserta pelatihan.

Berdasarkan pengamatan mengenai manejemen pembelajaran, sebagian besar pengajar sudah terlebih dahulu menyiapkan bahan materinya sehingga pembelajaran terencana dengan baik. Dengan didukung fasilitas yang lengkap di dalam kelas, kegiatan pengajaran menjadi efektif dan efisien. Waktu yang diberikan benar-benar dimanfaatkan oleh para dosen sehingga materi benar-benar tuntas. Tidak ketinggalan evaluasi atau diskusi dan tukar pendapat di akhir pembelajaran, semuanya rutin dilaksanakan.

Dari hal ini profesionalitas seorang pengajar benar-benar terlihat. Perencanaan pembelajaran yang tersedia, seni mengevaluasi, tukar pendapat, kemampuan dalam pengelolaan kelas, waktu dan media sudah seharusnya dimiliki oleh pengajar bahasa Arab di Indonesia agar proses pembelajaran menjadi lebih bernilai.

Program DTS Umm Al Qura Mekkah tahun 2018 dapat menjadi sebuah program alternatif yang dapat diduplikasi dan diimplementasikan dalam rangka meningkatkan pengetahuan budaya serta kompetensi pengajar, ustadz, dan dosen bahasa Arab di Indonesia.

\section{PENUTUP}

Berdasarkan hasil wawancara, observasi dan analisis data di atas, dapat diperoleh kesimpulan bahwa pelaksanaan DTS Umm Al Qura Mekkah Tahun 2018 dilaksanakan dengan mekanisme yang telah ditentukan yaitu: 1) persiapan dan rencana, yakni membangun koordinasi antar pihak dan membentuk tim panitia di masing-masing Negara; 2) Proses perekrutan, yakni 
Farid Permana: Refleksi Daurah Tadribiyah Di Universitas Umm Al Qura Mekkah Saudi Arabia

berkaitan dengan seleksi peserta yang berhak mengikuti program DTS. Tim Panitia mengumumkan secara terbuka melalui sebuah website perihal seleksi meliputi pemberkasan, tes tertulis dan tes lisan via telepon; 3) proses koordinasi pra keberangkatan, yaitu terkait kegiatan evaluasi awal untuk mengikuti DTS seperti perkenalan antar peserta dan tim panitia, arahanarahan dan penunjukan Ketua kelompok beserta unsurnya; 4) program inti DTS meliputi, pelatihan di dalam kelas, kunjungan sosial budaya Arab dan kegiatan Ibadah Umrah.

Kegiatan DTS dapat menjadi refleksi bagi kemajuan pendidikan bahasa Arab di Indonesia, khususnya yang terkait dengan kompetensi pedagogik, kompetensi keperibadian dan kompetensi profesional pengajar bahasa Arab di Indonesia. Dalam melaksanakan tugas sebagai pengajar bahasa Arab profesional, haruslah dilandasi oleh filosofis akademik dan prosedur kerja ilmiah, jujur, kritis, kreatif, terbuka, sederhana, merasa punya amanah dan penuh keikhlasan. Sikap ini menghendaki seorang guru bahasa Arab untuk senantiasa melaksanakan tugas dengan sebaik-baiknya dan selalu berusaha melaksanakan tugas keguruan yang diembannya dengan inovasi dan kreasi tiada henti.

\section{DAFTAR PUSTAKA}

Darunnajah, Informasi terkait seleksi peserta DTS Umm Al Qura Mekkah http://darunnajah.com/dauroh-gratis-2019-40-hari-di-makkah/ 2019.

Hamid, Muhammad Abdul, Dirasah 'An Manhaj Ta'lim al-Lugah Al-Arabiyah Ligairi Al-Nathiqina Biha Bijami'ah Al-Malik Sa'ud Fi Al Riyadh, Jurnal Al Jadid, Vol. 8 Nomor 1, 2008

Moekijat. Pengembangan dan Motivasi. Bandung: Pionir Jaya. 1990

Moloeng, Lexy J. Metodologi Penelitian Kualitatif Bandung: Rosdakarya. 2011

Mukhtar. Metode Praktis Penelitian Deskriptif Kualitatif. Jakarta: Referensi, 2013.

Suriansyah, A. Aslamiyah Ahmad dan Sulistiyana. Profesi Kependidikan: Perspektif Guru Profesional. Jakarta: Rajawali Pers. 2015.

Syuhendri, Pengelolaan Sekolah Untuk Mengembangkan Sumber Daya Manusia dan Implementasinya Pada Pembelaiaran IPA SD: Suatu Refleksi Hasil Short Course di New Zealand. 2012. 
Farid Permana: Refleksi Daurah Tadribiyah Di Universitas Umm Al Qura Mekkah Saudi Arabia

Tim Peserta DTS, Laporan Kegiatan Daurah Tadribiyah Shoifiyah Universitas Umm Al Qura Mekkah Angkatan X Tahun 1439 H, Dokumen tidak dipublikasikan. 2018

Yasin. Ahmad Fatah, Pengembangan Kompetensi Pedagogik Guru Pendidikan Agama Islam di Madrasah (Studi Kasus di MIN Malang I), "Jurnal eLQudwah Vol.1 Nomor 5, 2011 